\title{
Concrete properties in diaphragm walls embedded in non-cohesive soils
}

\author{
Magdalena Czopowska - Lewandowicz*
}

Faculty of Civil Engineering and Architecture, Opole University of Technology, Opole, Poland.

\begin{abstract}
Although diaphragm walls are massive and responsible structures whose building history has many years' tradition, the discovery of a variety of material faults is still common throughout their exploitation. Some of the most common ones are associated with the occurrence of leaks along the wall surface. This paper reports on the results of a study conducted into concrete quality in an existing building structure. The issues identified in this case include the potential penetration of groundwater and particles suspended in non-cohesive soils into the bentonite suspension and into the concrete mixture. The scope of the analysis also involved the possible occurrence of a mixing zone of bentonite suspension with the concrete mixture. The solutions presented in this paper were practically tested using an existing structure and the results confirm that the adopted approach needs to be thoroughly researched. The laboratory specimens derived from an unreinforced diaphragm wall were subjected to the following tests: concrete bulk density in the air-dried state, water absorption by concrete, depth of water penetration under pressure, compressive strength and determination of the quantitative phase composition test using X-ray diffraction method. The results clearly demonstrate the decrease of the concrete quality applied in a monolithic diaphragm wall in comparison to the reference samples taken at the phase when it was built. Due to the fact that it was impossible to identify the impact of the particular variables on the investigated structure, this paper focuses on their descriptive assessment. This discussion is based on the analysis of the results defining the physical and mechanical properties of the examined concrete coupled with observations made by the author and insights derived from literature.
\end{abstract}

\section{Introduction}

Diaphragm walls have been built since 1960s and play the role of the retaining structures for deep trenches, parts of underground structures and often play the role of a foundation. Most often they are realized as monolithic concrete structures. Due to the requirements that dedicated geotechnical facilities have to fulfill, there is a need of a constant control of the quality of the materials applied in their construction. The requirements set to the concretes applied in such structures are now higher than ever. This concerns not only fatigue strength,

\footnotetext{
* Corresponding author: m.czopowska-lewandowicz@po.opole.pl
} 
however, the primary focus is placed on the adequate service life of the final structures. As a result of the need to build diaphragm walls reaching considerable depths, i.e. in the range from several to a few dozen meters below ground level and the technology applied in building them, the possibility to directly control concrete quality is limited and in the lower section of the wall it is sometimes impossible [1]. In addition, the variety of the parameters that affect the parameters of concrete mixture throughout the phase when the structure is concreted are known to play a considerable role on the final quality of the structure. These parameters mainly include: contamination of the mixture by soil particles, influx of ground water and the risk of the potential mixing of bentonite suspension with the concrete mixture. Some of the sources in literature contain a remark that the penetration of ground water particles in the structure of the mixture is quite unlikely [2]. However, the considerable porosity of the concrete in the investigated wall and the leaks visible on its surface seem to contradict these claims [3].

The lack of the guarantee that fault-free homogeneous concrete monolith is constructed forms the principal practical problem associated with using diaphragm walls. Despite the long tradition of building such structures, the aspect associated with the concrete quality has not been thoroughly analyzed. We do not have sufficient information regarding the strength-related concrete parameters depending on the type of the bentonite applied in the suspension, level of ground water on a building site, as well as the profile of the soil in which the wall is embedded [4]. This problem plays a considerable role in the context of the fact that diaphragm walls form massive structures and support effective facilities, as this technology finds common application in urban agglomerations.

\section{Problem statement}

Monolithic diaphragm walls are concreted using the contractor method under the inert reinforcement by bentonite suspension. The role of the latter is associated with supporting trench walls and protection from soil collapse into the excavation. The composition of the concrete mixture and its consistence need to be selected in such a way to ensure that water is displaced from the bottom of the wall cavity; suspension does not segregate and does not set on the rods of reinforcing cages when the bentonite mixture is pumped into the trench $[1,5]$. In the consideration of the difficulties associated with the conditions of concreting and applied technology, it is difficult to gain the designed concrete properties in the constructed wall. This is attributable to the conditions to which the bentonite-concrete mixture is exposed as well as to the exposure of the concrete in the existing wall. These conditions can be classified into short-term factors - i.e. ones that occur throughout the time when the object is constructed as well as long-term ones - i.e. ones that occur throughout the service life of the structure [6]. Due to the installation of the diaphragm walls at considerable depths, we often have to face the influx of groundwater combined with all contaminations that are leached form the surrounding soils with them. This water sometimes contains aggressive compounds and can penetrate into the structure of the bentonite suspension and concrete mixture. The most probable scenario involves the production of a thin barrier between the adjacent soil and the constructed wall, which can limit the water influx inside of the monolith. However, there is no certainty if such a barrier comprising hydrated bentonite has a continuous structure and whether it occupies only some of the surface of the wall-soil interface. Apart from this, if the conditions lead to the water penetration inside the bentonite suspension, the density of this mixture will consequently decrease. This will lead to the possible collapse of soil particles inside the slurry trench and reduction decrease of the tightness of the protective bentonite barrier. Since both the suspension and the mixture are in motion during the concreting process, there is a high likelihood that the soil particles will penetrate into the concrete structure. 
Such contaminations form the reasons for the future fractures in the monolith. The possible contamination with soil particles is relative to the properties of the concrete mixture and primarily depends on the soil properties in a given location.

However, the most important factor that affects the concrete quality is associated with the potential occurrence of a mixing zone between the bentonite suspension and concrete mixture. This process occurs most effectively in the bottom section of the diaphragm wall. This is caused by the turbulence around the tremie pipe which is applied to feed the concrete mixture. The local deterioration in the concrete quality can impact the stability of the wall structure, since the binding of the bentonite suspension in the concrete mixture often results in the decrease of the concrete properties, which can lead to the occurrence of fissures or fractures[6-8]. The decrease of concrete quality also occurs in the upper part of the structure, and result from the deficiencies in the compaction process. Both factors contribute the increase of the porosity of the resulting structure.

Another aspect is related to the processes occurring throughout the phase when the wall is in normal service. Depending on the environment in which the wall is constructed, it is subjected to the action of groundwater, often containing aggressive elements, to the action of chlorides contained in salts, for instance when the diaphragm wall forms the retaining structure of a road and to the potential action of seawater and chemical substances. For the case when the wall is partly or completely exposed to direct environmental conditions, the concrete is subjected to the deterioration of the structure caused by freeze-thaw cycle and to considerable temperature gradients, which will lead to shear stress. The intensity of the impact of long-term factors on the constructed diaphragm wall is largely dependent on the concrete quality that is cast and the impact to the short-term factors. An increase of the water/cement (w/c) ratio resulting from the occurrence of a mixing zone of bentonite suspension with the concrete mixture as well as the penetration of the soil particles contained in groundwater leads to the increase of the concrete porosity, which is likely to accelerate the destructive effect of the environment on the constructed wall. In addition, if we have to do with a non-cohesive soil profile around the structure, the migration of groundwater will be considerably accelerated. We can also anticipate that the soil particles are included in the wall monolith and the process of mixing bentonite suspension with concrete mixture results in the decrease of the strength-related concrete parameters, which will be discussed in detail in the next section of this paper.

\section{Materials and methods}

\subsection{Characteristics of investigated structure}

The research applied a structure which is formed by a section of a diaphragm wall. This wall first played the role of a retaining structure to a trench - i.e. during the stage when the wall was erected, and at present it plays the role of a deep foundation under an office and commercial building. The analyzed diaphragm wall also forms a underground structure applied to retain an underground car park situated below the exisiting building, which is located on the outskirts of a Polish city, Poznań. During the construction works, the diaphragm walls were uncovered and steel pipe struts were supplemented to the supporting structure at the ends of the trench (Fig. 1). The struts were fabricated in sections with a length of $1.20 \mathrm{~m}$, and subsequently combined using a cap with a height of $0.60 \mathrm{~m}$. The investigated section of the wall was unreinforced and only provided a temporary support. The wall was set at a depth of $13.5 \mathrm{~m}$ below ground level, and the height of the wall was equal to $10.85 \mathrm{~m}$ (without the tie beam). The wall thickness was $0.63 \mathrm{~m}$. The examined structure is embedded in non-cohesive soils. The soils mainly consisted of medium-sized 
sands in semi-compact form and loamy sands with layers of silts and clayey soils. The level of groundwater in the vicinity of the constructed wall sections was identified to be at a depth of $8.10 \div 8.45 \mathrm{~m}$ below ground level.

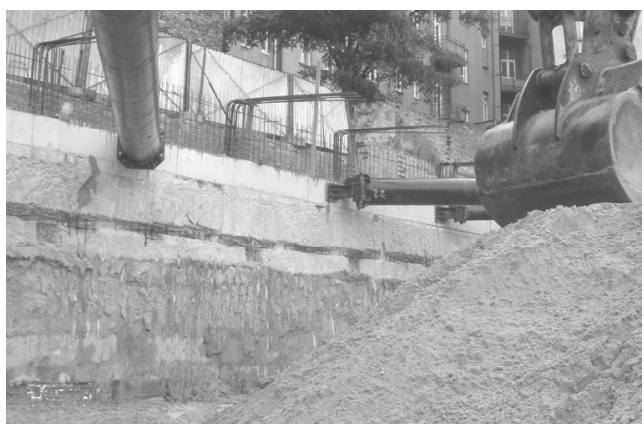

Fig.1. The picture of the tested diaphragm wall with the steel pipe struts.

The analyzed section of the structure was concreted from three successive mixer trucks. Samples were taken throughout all stages when the concrete structure was laid, and formed the source of reference for further comparisons. From each concrete batch, three cubeshaped specimens were taken out with the side of $15 \mathrm{~cm}$ each. They were kept in molds for 24 hours to prevent them from vibrations and loss of water. After this time, they were removed from the molds and immersed in water at the temperature of $20 \pm 5^{\circ} \mathrm{C}$ for the next 27 days.

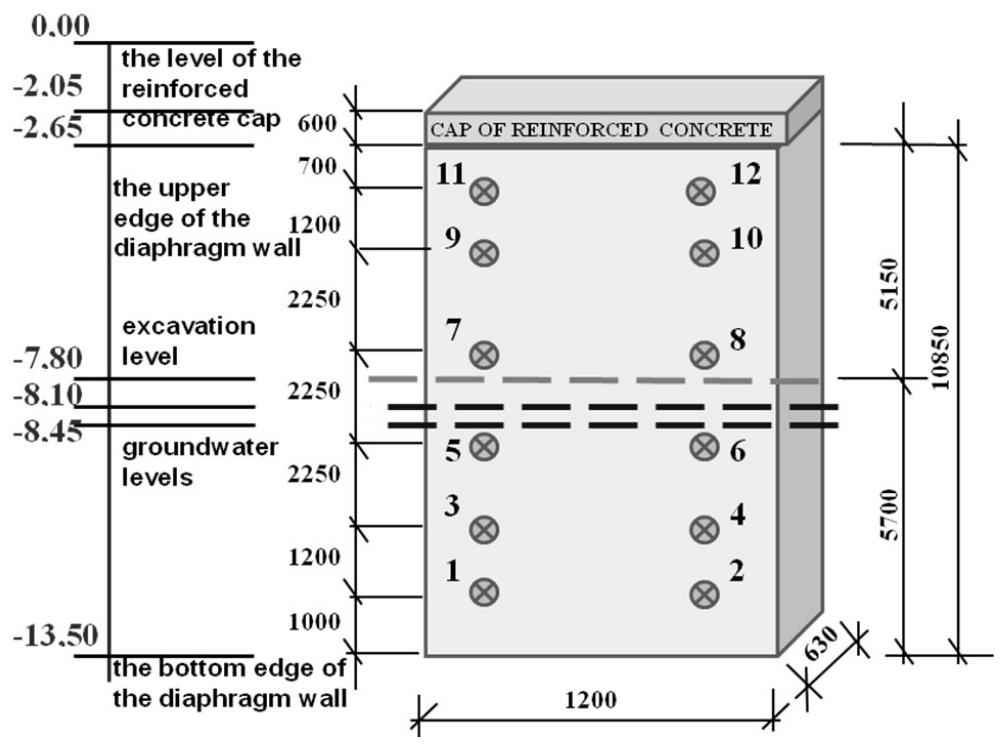

Fig.2. The scheme of the tested diaphragm wall with location of the drillings.

After the section of the wall that was used in the research was exposed, concrete samples were taken from them. Such samples were adequately protected and transferred to laboratory along with the reference samples. For the purposes of the present research, core drilling was used to obtain 12 samples with the diameter of $\varphi=100 \mathrm{~mm}$ and a length equal to the thickness of the wall. The diagram with the distribution of the extracted 
sampling locations is presented in Fig. 2. The samples were taken along seven sections of the wall while a greater density of the sampling was ensured in the lower and upper wall section, as the worst technical parameters of concrete were anticipated to occur in these parts. Each of the drilled holes was subjected to a visual inspection. On this basis, no confirmation of the segregation of concrete component could be established. The samples obtained from the drilling trials were later further separated for the purposes of further testing (Fig.3).

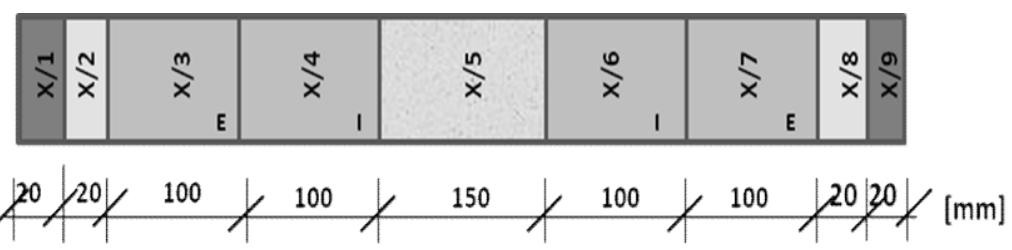

Fig.3. The separation of the drilling into research samples (X/1, X/9 - the external layer of the wall; $\mathrm{X} / 2, \mathrm{X} / 8$ - the laboratory specimens for determination of the quantitative phase composition test using X-ray diffraction method; X/3, X/5, X/6 - the laboratory specimens for concrete bulk density test in the air-dried state; $\mathrm{X} / 4, \mathrm{X} / 7$ - the laboratory specimens for water absorption by concrete test and depth of water penetration under pressure test; X/3, X/6 - the laboratory specimens for concrete compressive strength test).

In this manner, cylinder-shaped samples were derived with the diameter and height equal to $100 \mathrm{~mm}$. All laboratory specimens - both the ones derived from drilling as well as reference ones - were subjected to the same test program. The following program of testing included the following tests: concrete bulk density in the air-dried state, water absorption by concrete, penetration of water under pressure, and a compressive strength test. With the purpose of comparing the strength parameters of the reference cube-shaped specimens, and the cylindrical samples from the drillings, adequate coefficients were applied for conversion of the results. In accordance with the literature data, all results gained with regard to cylindrical samples were converted into the strength parameters for the specimens with the dimensions of $15 \times 15 \times 15 \mathrm{~cm}$.

In addition, the determination of phase composition was conducted by application of $\mathrm{X}$ ray diffraction method. This procedure applied selected 15-gram mortar samples (aggregate with particle size above $4 \mathrm{~mm}$ was rejected) taken from the internal side of the wall (i.e. taken from a depth of $3 \mathrm{~cm}$ from the surface). This material was ground and the quartering procedure was applied to gain 2-gram laboratory specimens used in the tests. The determination of the above physical and mechanical properties of the material obtained from drilling was performed by application of the external samples (i.e. originating from the part of wall close to the monolith surface) as well as using the internal samples (i.e. ones taken from the inside part of the wall). The wall was built using a concrete mix derived from a ready-mixed concrete plant, whose production complied with the requirements of the current standard PN-EN 206-1:2003 [9] as well as the norms regarding the production of diaphragm walls PN-EN 1538:2002 [5].

The water/cement (w/c) ratio of the mix was prepared in accordance with the guidelines detailed with regard to realization of the structures of this kind $(\mathrm{w} / \mathrm{c} \leq 0.55)$, as it $\mathrm{w} / \mathrm{c}$ ratio was equal to 0.52 and the air content in the mix was determined to be around $2 \%$. In accordance with the guidelines given in [5], the ratio of cement and mineral admixtures should be in the range from $400 \div 550 \mathrm{~kg} / \mathrm{m}^{3}$, and the mix should be produced on the basis of natural aggregate. A summary with the details of the composition of the mixture can be found in Table 1. The consistence of the concrete mixture delivered to the site was manufactured to $\mathrm{S} 4$ class and the parameters were determined on the basis of a slump test (cone subsided $20 \mathrm{~cm}$ ). Such consistence was gained as a result of using plasticizer addition 
in the amount of $0.50 \%$ and a super plasticizer addition in the amount of $0.55 \%$ in relation to the cement weight. The designed concrete had $\mathrm{C} 25 / 30$ class and the watertighntess rate was W8.

Table 1. The composition of the concrete mixture.

\begin{tabular}{|c|c|c|}
\hline \multicolumn{2}{|r|}{ Component } & The composition of the concrete \\
\hline \multirow{3}{*}{ Aggregate } & sand $0 \div 2 \mathrm{~mm}$ & 635.0 \\
\hline & gravel - fraction $2 \div 8 \mathrm{~mm}$ & 549.0 \\
\hline & gravel - fraction $8 \div 16 \mathrm{~mm}$ & 532.0 \\
\hline \multicolumn{2}{|c|}{ Cement CEM III/A 32.5 L-LH } & 350.0 \\
\hline \multicolumn{2}{|c|}{ Fly ash } & 65.0 \\
\hline \multicolumn{2}{|r|}{ Water } & 185.0 \\
\hline \multicolumn{2}{|c|}{ Plasticizers BV 18 SC } & 1.75 \\
\hline \multicolumn{2}{|c|}{ Superplasticizers Glenium Sky 519} & 1.93 \\
\hline
\end{tabular}

The preparation of the bentonite suspension applied TEQGEL HD bentonite, which was always prepared in batches 24 hours prior to its use in the trench. The bentonite powder was mixed with water at the ratios so as to ensure that the density of the suspension was equal to $1.035 \mathrm{~g} / \mathrm{cm}^{3}$ - which is in conformity with the standards applied in the construction of diaphragm walls. Under the assumption of a constant density, the content of the dry bentonite was equal to around $4 \%$.

\subsection{Results and discussion}

On the basis of the analysis of the results, we can clearly see that the worst technical concrete parameters were recorded in the areas that are close to the top and bottom parts of the wall. It is also noteworthy that the majority of the laboratory specimens that were taken demonstrated worse properties from the ones gained in the reference samples. The chart in Fig. 4 shows a considerable increase of the water absorption by concrete in the top section of the wall (by around 35\%). The value of the water absorption in this part is close to $8.5 \%$, which demonstrates that the concrete in this wall part has a poor quality. This result can be due to the increased concrete porosity, and the resulting decrease of the mass density (Fig. 5), which comes as a consequence of the worse properties of concrete compacting in this part of the wall. The reason could also be associated with the inadequate spill out of the edges of the concrete mixture in the excavation that is often performed with the purpose of the displacement of bentonite slurry. The results gained from the analysis demonstrated that the particles of the suspension remained in the concrete structure. The data regarding the penetration of water under pressure shows very similar image of the concrete. With regard to this parameter, worse values were gained in the upper part of the wall. However, we can note that the watertightness rate of W8 recommended for diaphragm walls was preserved in the entire monolith. In the bottom wall part, the values of both absorbability and penetration of water under pressure were at a comparable level to the reference samples. In addition, during the test involving water absorption by concrete, the observations offered a conclusion that the process of laboratory specimens drying takes considerably longer in comparison to the reference samples. 


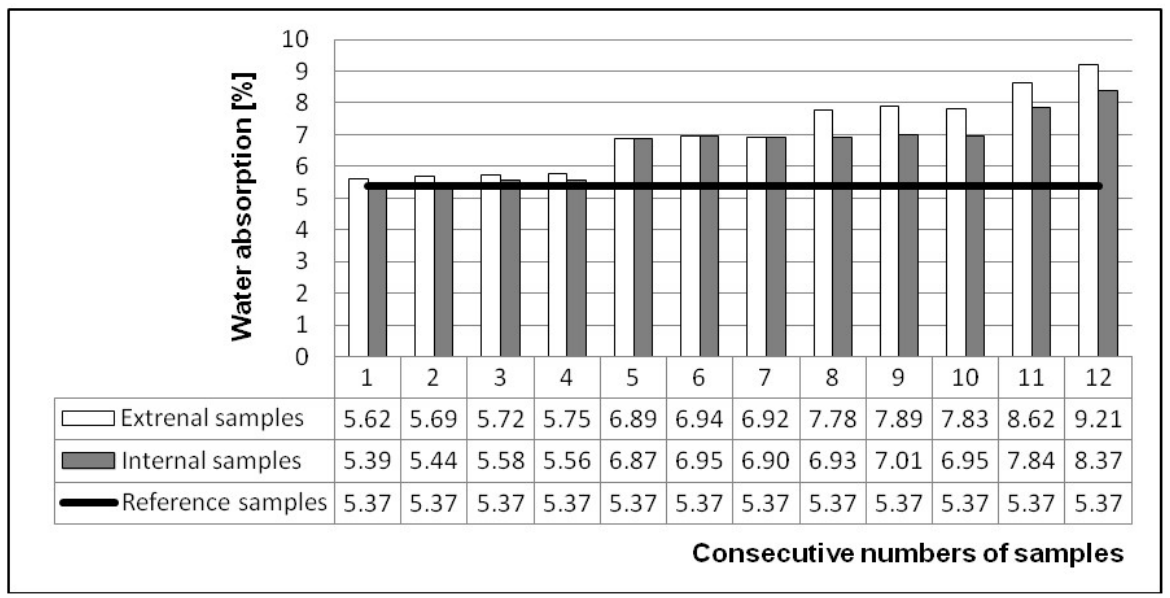

Fig.4. The results of the water absorption test of the concrete samples from the diaphragm wall (extrenal samples- $\mathrm{x} / 7$, internal samples- $\mathrm{x} / 4$ ) and the reference samples.

The time needed to obtain dry mass of the samples derived from the examined wall was equal to as much as 32 days. This could be associated with the occurrence of a mixing zone of bentonite suspension with the concrete mixture. The water absorbed by the bentonite granules integrated into the structure of concrete evaporates more slowly during drying in comparison to the samples not containing bentonite. Fig. 5 contains the distribution of the volume density both along the height as well as width of the wall. We can clearly see the decrease of this parameter in the top and bottom wall parts. The difference amounts to as much as $11 \%$. In the middle part of the structure, the results are also lower from the ones that were determined in the reference samples; however, the decrease in this case is equal to $2.5 \%$.

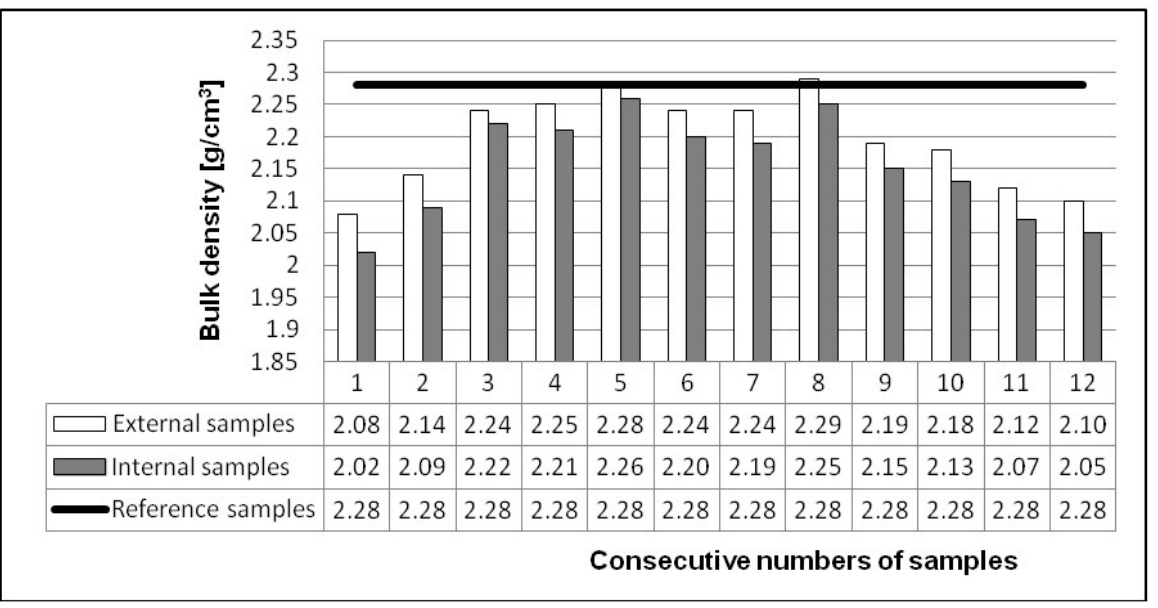

Fig.5. The results of the bulk density test of the concrete samples from the diaphragm wall (extrenal samples- $x / 3$, internal samples- $x / 5$ and $x / 6$ ) and the reference samples.

The results gained from the compressive fatigue tests raise more important concerns. All recorded results are lower from the levels gained in the reference samples. As we can see in the chart in Fig. 6, the differences in the fatigue strength are varied both along the height as well as width of the wall. We can note a tendency that the results gained in the laboratory specimens originating from the outermost part of the structure are lower from the 
ones gained in its inside part. This is associated with the penetration of granules in the suspension through the surface inside the wall is constructed. The considerable decrease of the fatigue parameter was recorded in the samples taken in the parts closest to the top and bottom of the wall. This decrease is in the range of as much as $50 \%$. This is undoubtedly associated with the turbulence around tremie pipe and mixing of the suspension with the concrete in the base of the structure as well as the penetration of groundwater into the mixture, as groundwater level affected the building phase stage of the wall. However, we can remark that in some parts of the structure, concrete does not fulfill the minimum requirements with regard to fatigue strength established for diaphragm walls, i.e. $32 \mathrm{MPa}$ $[1]$.

In addition, the penetration of groundwater into the mixture was in this case promoted due to the presence of non-cohesive soils on the building site, as such soils are not capable of holding water in the structure but allow it to flow freely through them. As a result of the water influx inside the wall, soil particles penetrate into the concrete structure and result in the formation of microfissures and cracks. In turn, these conditions lead to a considerable decrease of the concrete strength in the base part of the wall, which is certain to have an effect on the service life of the entire structure.

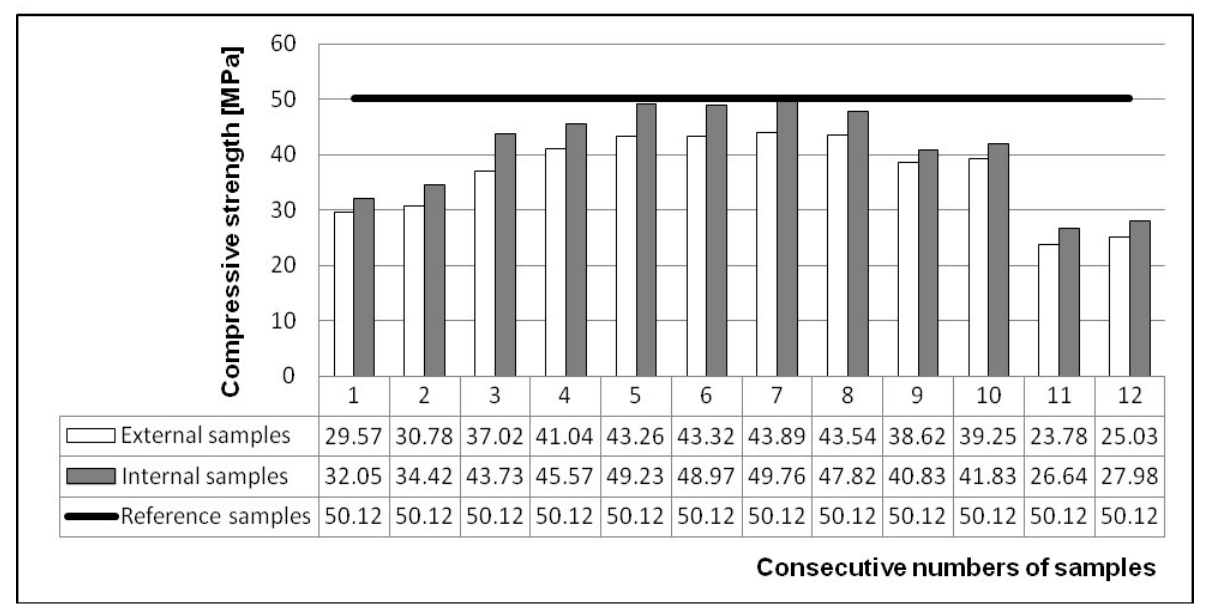

Fig.6. The results of the compressive strength test of the concrete samples from the diaphragm wall (extrenal samples- $x / 3$, internal samples- $x / 6$ ) and the reference samples.

A similar decrease of the strength parameter was obtained in the top part of the wall. In this case, the outcome is associated with the occurrence of a mixing zone of bentonite suspension with the concrete mixture as well as the deficiencies during the compacting phase of concreting. On the basis of the analysis of the results, we can observe that the volumetric density of the samples obtained from the outer surface of the diaphragm is higher in comparison to the samples taken from the inner part of the diaphragm. However, the compressive strength measured in the same samples is greater for the case of the samples derived from the innermost part of the diaphragm. Although this is apparently irrational, the recorded outcome could be associated with the occurrence of the soil particles and bentonite in the concrete pores in the outermost part of the diaphragm. This results in an increase of the weight of the investigated samples as well as a slight increase of the volumetric density. However, such inclusions negatively affect the level of the compressive strength.

After this data is converted into concrete classes, the differences expressed in terms of concrete quality are considerable, in particular along the part from the top to the base of the 
wall. The differences in relation to the design are equal to as much as two quality classes, whereas the comparison to the reference concrete samples - the difference is four classes. By comparing the results gained from this study and the ones found in the literature, we can find that the values recorded in the walls embedded in non-cohesive soil are only slightly different from the ones that are gained for the diaphragm walls embedded in cohesive soils [6]. In the former case, the results were worse, which demonstrates the role of the groundwater in the formation of considerable pores in the concrete used in the examined monolith.

In addition, in the samples that were extracted from the depth of around $3 \mathrm{~cm}$ from the outer wall surface, the testing of the quantitative phase composition test using X-ray diffraction method was performed. The results of this test did not demonstrate the presence of bentonite in the laboratory specimens; hence, its presence in the concrete mix cannot be established with a high level of certainty. However, as other insights into the area suggest, the identification of the presence of bentonite is only possible when its volume fraction in relation to the cement mass is in the range of dozen percent. Hence, the presence of the suspension in the concrete mixture and later bentonite in the porous structure is only possible in an indirect manner, that is by analyzing the results of concrete testing and taking into account the variable conditions present when a given structure is built [7]. In this case, the procedure concerned with the search for soil inclusion in the examined facility was difficult, as the soil around the wall consisted mainly of soils, whose composition is dominated by quartz which also forms part in concrete. However, this test also demonstrated the presence of loamy particles, and this forms the evidence for the penetration of the soil into the diaphragm wall.

\section{Conclusions}

On the basis of the analysis of the results of research involving laboratory specimens derived from drilling performed in an existing diaphragm wall, we can clearly note that the physical and mechanical parameters of the examined concrete are considerably distinct from the properties of the material that was delivered to the building site in the past. The concrete samples derived from the facility do not form a homogenous monolith that is faultfree. This condition is relative both with the impact of the short-term factor during the concreting stage of the building. This effect is particularly due to the occurrence of a mixing zone of bentonite suspension with the concrete mixture. A differentiation of the material properties was recorded along the height and the thickness of the wall, which is certain to have a negative effect on the performance of the structure. The area raising most concern is associated with the considerable decrease of the compressive strength of the concrete in the structure. This is due to the increase of the concrete porosity. The existence of non-cohesive soils in the area of the wall has a considerable effect on this. The existence of such soils promotes the migration of the groundwater into the concrete mixture throughout the phase when the facility was realized. In addition, the lowest part of the wall is located on the ground that is surrounded by medium-sized sands. In contrast, the area located near the central part of the wall comprises loamy sands with layers of clayey soils and silts. Such a soil profile also affected the differentiation of the results recorded along the height of the diaphragm. This fact is coupled with the occurrence of a mixing zone of bentonite suspension with the concrete mixture resulted in an increase of the w/c ratio. Water from the suspension migrates into the mixture, and after the concrete sets in the wall, hollow spaces comprising small amounts of bentonite appear in the structure, a fact that is quite difficult to establish by application of the modern engineering methods. However, the presence of bentonite in the concrete structure can be confirmed by the longer period needed to dry the samples after the test of water absorption. The considerable porosity of 
the structure in its upper part is related to the insufficient degree in which the mixture was compacted in this region. The quality of the monolith is additionally decreased by the fact that soil particles were identified in the concrete structure. This is also due to the occurrence of non-cohesive soils, whose particles were displaced and circulated freely at the phase when the diaphragm wall was concreted.

Due to the technology in which diaphragm walls are constructed, there is no possibility of avoiding conditions in which adverse factors affect the structures when they are built. It is possible to eliminate the negative their impact by performing investigations of the concrete structure in terms of its porosity and by conducting attempts aimed at providing watertightness of the applied concrete mixture. However, this objective requires further laboratory testing and subsequent adaptation of concrete mixtures applied in actual conditions.

\section{References}

1. Base Geotech Pty Ltd., Specification for Diaphgram Wall, ( 2012)

2. R. Spruit, F. van Tol, W. Broere, E. Slob, E. Niederleithinger, Detection of anomalies in diaphragm walls with crosshole sonic logging, Canadian Geotechnical Journal, 51(4), p. 369-380, (2014)

3. I.H.Wong, Experience with waterproofness of basements constructed of concrete diaphragm walls in Singapore, Tunnelling and Underground Space Technology, 12, 4, p. 491-495, (1997)

4. W. Powrie, C. Kantartzi, Ground response during diaphragm wall installation in clay: centrifuge model tests, Géotechnique, 46, 4, p. 725-739, (1996)

5. PN-EN 1538:2002, Wykonawstwo specjalistycznych robót geotechnicznych. Ściany szczelinowe, (2002)

6. M. Czopowska-Lewandowicz, Badania wtaściwości betonu w ścianach szczelinowych, 61. Konferencja naukowa KILiW i KN PZITB, Krynica (2015)

7. M. Czopowska-Lewandowicz, Próby identyfikacji bentonitu $w$ betonie ściany szczelinowej, Materiały Budowlane, 528, 8, p. 67-69, (2016)

8. J.H. Dalen Van, J.W. Bosch, W. Broere, Concrete Flow in Diaphragm Wall Panels: A Full-Scale In-Situ Test, Geotechnical Risk and Safety V, Rotterdam (2015)

9. PN-EN 206-1:2003, Beton. Cz.1: Wymagania, właściwości, produkcja i zgodność, (2003) 